\title{
Long-term results of laparoscopic surgery and open surgery for colorectal cancer in Huaihe River Basin of China
}

\author{
Jing $\mathrm{LI}^{1}$, Jianguang JIA ${ }^{1}$, Bo XIE ${ }^{1}$, Chengwu PAN ${ }^{1}$, Chensong ZHANG ${ }^{1}$, Lei LI ${ }^{1}$, Hu WANG ${ }^{1}$, Hongbo $\mathrm{LI}^{1}$, \\ Jiachi MA ${ }^{1 *}$ (D)
}

\begin{abstract}
In this study, we aimed to compare clinical efficacy of laparoscopic surgery and open surgery for colorectal cancer in the Huaihe River Basin in China. A total of 92 patients with colorectal cancer were selected as subjects. Patients were divided into control group (open surgery, $\mathrm{n}=27$ cases) and test group (laparoscopic surgery, $\mathrm{n}=28$ cases). Our results showed that the duration of operation $(122.54 \pm 14.85) \mathrm{min}$ and length of incision $(4.51 \pm 1.065) \mathrm{cm}$ were shorter in the experimental group than those in the control group. The intraoperative blood loss of the experimental group was $(161.12 \pm 10.694) \mathrm{ml}$, which was less than that of the control group $(218.53 \pm 15.369) \mathrm{ml}(P<0.05)$. Patients in the experimental group have higher Five-year survival rate and lower incidence of postoperative complications than those in the control group (all $P<0.05$ ). In conclusion, in the treatment of colorectal cancer, laparoscopic surgery has a better clinical effect than open surgery, which is worthy of clinical application.
\end{abstract}

Keywords: laparoscopic surgery; open surgery; colorectal cancer.

Practical Application: Thtough compare the clinical efficacies of laparoscopic surgery and open surgery for colorectal cancer in the Huaihe River Basin in China, we found that laparoscopic surgery has a better clinical effect than open surgery in the treatment of colorectal cancer, which is worthy of clinical application.

\section{Introduction}

Colorectal cancer is a common malignant tumor that is highly prevalent in the human body (Bekaii-Saab, 2018), which is a disease with high morbidity and high mortality (Fahim et al., 2019; Wieczorska et al., 2020; Yeh et al., 2019; Zhao et al., 2019). It can affect the patient's cecum, ascending colon, transverse colon, descending colon, sigmoid colon, rectum and other parts (Chen et al., 2018a). Ki-67 positive rate and its positive value are the expression of oncogene expression, and also the basis of malignant biological behavior and histopathological changes of colorectal cancer. Surgical treatment is an effective method to inhibit the disease of patients. The influence of different surgical methods on the oncogene and the prognosis of patients are different. Colorectal cancer is a malignant tumor that is common in clinical practice and its incidence is high. Early colorectal cancer patients have only clinical symptoms such as abdominal distension and dyspepsia, which rarely cause patients to pay attention. As a result, most patients go to the hospital for treatment, and their condition has progressed to the advanced stage, which poses a serious threat to the patient's life.

Laparotomy was mainly used to treat colorectal cancer in the past years, but this treatment is more traumatic to the patient (Zhao et al., 2014; Tajima et al., 2017; Kojima et al., 2019). Postoperative patients are prone to multiple complications and the prognosis is not satisfactory (Kim \& Kim, 2017; Chen et al., 2018b; Bellio et al., 2019). Therefore, actively exploring alternative treatments for colorectal cancer has become the focus of clinical research (Li et al., 2021; Mostafa et al., 2021; Jouki et al., 2020). In recent years, with the continuous development of minimally invasive techniques, laparoscopic surgery has been widely used in clinical treatment because of its small surgical trauma, low amount of bleeding, and rapid recovery of postoperative patients (Hamabe et al., 2019; Tajima et al., 2017; Hamabe et al., 2019; Iwamoto et al., 2019). However, the clinical effect of laparoscopic surgery for colorectal cancer is still controversial (Pei et al., 2019; Mekic et al., 2018; Zhou et al., 2019). The Huaihe River Basin is located in eastern China, between the Yangtze River and the Yellow River. Due to there is no relevant research to explore the clinical efficacy of laparoscopic surgery and open surgery for colorectal cancer in the Huaihe River Basin in China, this study compared the clinical efficacy of open surgery and laparoscopic surgery for colorectal cancer, and explored the long-term efficacy of abdominal laparoscopic surgery and open surgery for colorectal cancer. Therefore, it is scientific basis for the efficacy and safety of abdominal laparoscopic surgery for patients with colorectal cancer in the Huaihe River population in China.

\section{Materials and methods}

\subsection{Participating object}

A total of 92 patients with colorectal cancer admitted to a hospital in Huaihe River Basin of China from 2017.02 to 2019.02 were selected as subjects. According to the random number table, 46 patients were divided into control group and 
experimental group according to different surgical methods. The study was approved by the hospital ethics committee.

\subsection{Inclusion and exclusion criteria}

Inclusion criteria: Participants met the diagnostic criteria for colorectal cancer; participants were informed consent and signed informed consent. Exclusion criteria: those with other malignant tumors; those with serious mental, brain, liver, kidney and other important organ diseases; those who are allergic to anesthetic drugs.

\subsection{Methods and research indicators}

Patients in the control group were treated with open surgery. Patients in the experimental group were treated with laparoscopic surgery. The specific procedure is as follows. The artificial pneumoperitoneum was established first, and the pneumoperitoneum pressure was maintained at about $12 \mathrm{mmHg}$ $(1 \mathrm{mmHg}=0.133 \mathrm{kPa})$. Laparoscopy and instrumentation were performed using a 5-hole method; tumors were observed by laparoscopy to determine tumor location. Then use the operating instrument to clamp and cut off the blood vessels around the tumor, remove the tumor (note the integrity of the colon and mesorectum when removing the tumor), and clean the surrounding regional lymph nodes. Rinse the abdominal cavity area and juxtapose the drainage tube for drainage; if there is no bleeding, close the abdominal cavity layer by layer. Open surgery and laparoscopic surgery were used to compare and observe the clinical efficacy, Ki-67 expression (which was taken after surgery) and survival rate, as well as complications and 5-year survival rate.

\section{Results}

\subsection{Comparison of general characteristics of research subjects}

The mean age of the subjects in the experimental group was $(56.71 \pm 4.33)$ years old, and the mean age of the subjects in the control group was $(56.04 \pm 3.59)$ years. There was no statistically significant difference between the two groups $(t=0.803, P)$. $=0.424)$. The experimental group had 40 cases under the age of 60 , accounting for $86.96 \%$. The control group had 38 cases under the age of 60 , accounting for $82.61 \%$. In the experimental group, 31 males, accounting for $67.39 \%$, and 31 males in the control group, accounting for $71.74 \%$. In the experimental group, there were 21 cases of junior high school and below, accounting for $45.65 \%$. The control group had 23 cases of junior high school and below, accounting for $50.0 \%$. There were no significant differences in age, gender and educational level between the experimental group and the control group $(P>0.05)$. The results are shown in Table 1.

\subsection{Comparison of clinical effects after surgery}

The mean duration (Mean \pm SD) of operation was (122.54 \pm $14.85) \mathrm{min}$ in the study group and $(151.60 \pm 19.81) \mathrm{min}$ in the control group. The difference between the two groups was statistically significant $(t=-7.960, P<0.05)$. The mean intraoperative blood loss was $(161.12 \pm 10.694) \mathrm{ml}$ in the experimental group and $(218.53 \pm 15.369) \mathrm{ml}$ in the control group. The difference between the two groups was statistically significant $(t=-20.798$, $P<0.05)$. The average incision length of the study group was $(4.51 \pm 1.065) \mathrm{cm}$, and the average incision length of the control group was $(13.14 \pm 2.327) \mathrm{cm}$. The difference between the two groups was statistically significant $(t=-22.891, P<0.05)$. There were 4 cases of complications in the experimental group (incision infection, pulmonary infection, anastomotic hemorrhage and intestinal obstruction in 1 case), accounting for $8.69 \%$; 12 cases in the control group ( 4 cases of wound infection and 2 cases of pulmonary infection) There were 3 cases of anastomotic hemorrhage, 2 cases of intestinal obstruction and 1 case of lower extremity venous thrombosis, accounting for $26.08 \%$. The difference between the two groups was statistically significant $\left(\chi^{2}=4.842, P<0.05\right)$.

In the experimental group, 30 patients survived 5 years after surgery, accounting for $65.22 \%$. In the control group, 11 patients survived 5 years after surgery, accounting for $23.91 \%$. The difference between the two groups was statistically significant $\left(\chi^{2}=15.883\right.$, $P<0.05)$. In the experimental group, 21 cases were positive for Ki-67 expression after surgery, accounting for $45.65 \%$; 41 cases with positive expression of Ki-67 after operation in the control group were $89.13 \%$; the difference between the two groups was statistically significant. $(\chi 2=19.785, P<0.05)$. The results are shown in Table 2.

\section{Discussion}

The pathogenesis of colorectal cancer is mainly related to chronic inflammation of the large intestine, colorectal adenoma, genetic factors, etc (Sasso \& Latella, 2018; Gaspar-

Table 1. Comparison of general characteristics of research subjects.

\begin{tabular}{|c|c|c|c|c|c|c|}
\hline \multirow{2}{*}{ Variables } & \multicolumn{2}{|c|}{ Experimental group $(\mathrm{n}=46)$} & \multicolumn{2}{|c|}{ Control group $(n=46)$} & \multirow{2}{*}{$\chi^{2}$} & \multirow{2}{*}{$\mathrm{P}$} \\
\hline & $\mathrm{n}$ & $\%$ & $\mathrm{n}$ & $\%$ & & \\
\hline Age group (ys) & & & & & 0.803 & 0.424 \\
\hline$<60$ & 40 & 86.96 & 38 & 82.61 & 0.337 & 0.562 \\
\hline$\geq 60$ & 6 & 13.04 & 8 & 17.39 & & \\
\hline \multicolumn{7}{|l|}{ Gender } \\
\hline Male & 31 & 67.39 & 33 & 71.74 & 0.205 & 0.65 \\
\hline Female & 15 & 32.61 & 13 & 28.26 & & \\
\hline \multicolumn{7}{|l|}{ Educational level } \\
\hline Junior high school and below & 21 & 45.65 & 23 & 50.00 & 0.174 & 0.676 \\
\hline High school and above & 25 & 54.35 & 23 & 50.00 & & \\
\hline
\end{tabular}


Table 2. Comparison of clinical effects after surgery.

\begin{tabular}{|c|c|c|c|c|c|c|}
\hline \multirow{2}{*}{ Variables } & \multirow{2}{*}{\multicolumn{2}{|c|}{$\begin{array}{c}\text { Experimental group }(\mathrm{n}=46) \\
n(\%) \text { or Mean } \pm S D\end{array}$}} & \multirow{2}{*}{\multicolumn{2}{|c|}{$\begin{array}{c}\text { Control group }(\mathrm{n}=46) \\
n(\%) \text { or Mean } \pm S D\end{array}$}} & \multirow{2}{*}{$\chi^{2}$ or $t$} & \multirow{2}{*}{$P$} \\
\hline & & & & & & \\
\hline Duration of surgery $(\mathrm{min})$ & \multicolumn{2}{|c|}{$122.54 \pm 14.85$} & \multicolumn{2}{|c|}{$151.60 \pm 19.81$} & -7.960 & $<0.001$ \\
\hline Intraoperative blood loss (ml) & \multicolumn{2}{|c|}{$161.12 \pm 10.694$} & \multicolumn{2}{|c|}{$218.53 \pm 15.369$} & -20.798 & $<0.001$ \\
\hline Incision length (cm) & \multicolumn{2}{|c|}{$4.51 \pm 1.065$} & \multicolumn{2}{|c|}{$13.14 \pm 2.327$} & -22.891 & $<0.001$ \\
\hline \multicolumn{7}{|l|}{ Complication } \\
\hline Incision infection & \multicolumn{2}{|c|}{1} & \multicolumn{2}{|c|}{4} & 4.842 & 0.028 \\
\hline lung infection & \multicolumn{2}{|c|}{1} & \multicolumn{2}{|c|}{2} & & \\
\hline Anastomotic bleeding & \multicolumn{2}{|c|}{1} & \multicolumn{2}{|c|}{3} & & \\
\hline Intestinal obstruction & \multicolumn{2}{|c|}{1} & \multicolumn{2}{|c|}{2} & & \\
\hline Lower limb venous thrombosis & \multicolumn{2}{|c|}{0} & \multicolumn{2}{|c|}{1} & & \\
\hline No complications & \multicolumn{2}{|c|}{42} & \multicolumn{2}{|c|}{34} & & \\
\hline \multicolumn{7}{|l|}{ 5-year survival rate } \\
\hline Yes & 30 & 65.22 & 11 & 23.91 & 15.883 & $<0.001$ \\
\hline No & 16 & 34.78 & 35 & 76.09 & & \\
\hline \multicolumn{7}{|l|}{ Ki-67 } \\
\hline Positive & 21 & 45.65 & 41 & 89.13 & 19.785 & $<0.001$ \\
\hline Negative & 25 & 54.35 & 5 & 10.87 & & \\
\hline
\end{tabular}

Pintiliescu et al., 2020; Balthazar et al., 2021; Rafiq et al., 2020). Surgical treatment is an effective solution to bring the gospel to the majority of patients. However, in radical surgery, to improve the prognosis and judge the prognosis, it is necessary to face up to the specificity of the affected part. Eliminating postoperative complications and recurrence rates has an adverse effect on the quality of life and quality of life of patients (Cui et al., 2018). The speed of proliferation of Ki-67 cells accelerated after surgery, which accelerated the deterioration of the patient's condition (Digiacomo et al., 2019). The choice of laparoscopic surgery not only makes it possible to find small lesions that cannot be found by open surgery, but also has a comparative advantage in reducing the local recurrence rate and surgical operation of the tumor (Fahim et al., 2019; Ahiko et al., 2019). In addition, the feasibility and safety have been fully confirmed by the followup medicine.

Colorectal cancer is one of the most common malignant tumors of the digestive tract in the clinic (Fahim et al., 2019; Gachpazan et al., 2019). Open surgery is more traumatic to patients, and postoperative patients have slower recovery and higher complication rates (Zhao et al., 2014). Laparoscopic surgery has been gradually applied to clinical work because of its small trauma, less patient pain, and low postoperative complications (Bellio et al., 2019; Bell et al., 2019; Chiu et al., 2019). However, the anatomical location of the colorectal is more complicated, and laparoscopic surgery may not completely remove the lesion, resulting in a higher recurrence rate (Hamabe et al., 2019; Igder et al., 2020). This study explored the clinical efficacy of laparoscopic surgery for colorectal cancer, and aims to provide a reference for clinical practice.

The results of this study showed that the duration of surgery and the length of the incision in the experimental group were shorter than those in the control group, and the difference was statistically significant. The amount of intraoperative blood loss in the experimental group was lower than that in the control group, and the difference was statistically significant. The results suggest that, compared with open surgery, the duration of surgery and the length of the incision in laparoscopic surgery are shorter, and the amount of intraoperative blood loss is less. The results of this study also showed that the incidence of complications in the experimental group was lower than that in the control group, and the difference was statistically significant. The results suggest that laparoscopic surgery is safer than traditional open surgery.

Part of the operation steps of the traditional open surgery are limited by the visual field, and the blind and rough blister anatomy is not fine, which leads to intraoperative bleeding and poor prognosis. Laparoscopic surgery, as a new treatment method, is more advantageous in the treatment of patients' diseases than in traditional open surgery. Based on the comparison of the treatment practice and experimental results of this study, neoadjuvant chemotherapy is effective for colorectal cancer patients, and the contrast effect is obvious in the postoperative patient survival rate and clinical efficacy. In this study, the 5-year survival rate of the observation group was $65.22 \%$ (30/46), which was significantly higher than that of the control group $(23.91 \%$ $(11 / 46))$. The difference was statistically significant $(P<0.05)$. The expression of Ki-67 positive and Ki-67 positive in the control group was significantly higher than that in the observation group, and the difference was statistically significant $(\mathrm{P}<0.05)$. This study demonstrates that laparoscopic surgery is a minimally invasive procedure. In the new therapeutic field, the activity of the surrounding tissues and organs, especially the pelvic tissue, is achieved by accurately and excising the distal rectum.

\section{Conclusion}

In summary, laparoscopic surgery has a better clinical effect than laparotomy, which can shorten the duration of surgery and the length of the incision, reduce the amount of intraoperative blood loss, and reduce the incidence of postoperative complications. At the same time, laparoscopic surgery can help to promote the early recovery of colorectal cancer patients. Abdominal laparoscopic surgery is effective in patients with colorectal 
cancer and has high clinical efficacy and safety. Especially in the 5-year survival rate of patients with prognosis and the rate of cancer cell proliferation, it has significant curative effect and is worthy of clinical promotion.

\section{Conflict of Interest}

The author declare that they have no conflict of interest.

\section{References}

Ahiko, Y., Shida, D., Horie, T., Tanabe, T., Takamizawa, Y., Sakamoto, R., Moritani, K., Tsukamoto, S., \& Kanemitsu, Y. (2019). Controlling nutritional status (CONUT) score as a preoperative risk assessment index for older patients with colorectal cancer. BMC Cancer, 19(1), 946. http://dx.doi.org/10.1186/s12885-019-6218-8. PMid:31690275.

Balthazar, C. F., Moura, N. A., Romualdo, G. R., Rocha, R. S., Pimentel, T. C., Esmerino, E. A., Freitas, M. Q., Santillo, A., Silva, M. C., Barbisan, L. F., Cruz, A. G., \& Albenzio, M. (2021). Synbiotic sheep milk ice cream reduces chemically induced mouse colon carcinogenesis. Journal of Dairy Science, 104(7), 7406-7414. http:// dx.doi.org/10.3168/jds.2020-19979. PMid:33934866.

Bekaii-Saab T. (2018). How I treat metastatic colorectal cancer. Clinical advances in hematology \& oncology: H\&O, 18(9), 2-6.

Bell, S., Kong, J. C., Carne, P. W. G., Chin, M., Simpson, P., Farmer, C., \& Warrier, S. K. (2019). Oncological safety of laparoscopic versus open colorectal cancer surgery in obesity: a systematic review and meta-analysis. ANZ Journal of Surgery, 89(12), 1549-1555. http:// dx.doi.org/10.1111/ans.15081. PMid:30989792.

Bellio, G., Troian, M., Pasquali, A., \& Manzini, N. (2019). Outcomes of laparoscopic surgery for pT3/pT4 colorectal cancer in young vs. old patients. Minerva Chirurgica, 74(4), 297-303. http://dx.doi. org/10.23736/S0026-4733.19.07895-7. PMid:30761829.

Chen, C. F., Lin, Y. C., Tsai, H. L., Huang, C. W., Yeh, Y. S., Ma, C. J., Lu, C. Y., Hu, H. M., Shih, H. Y., Shih, Y. L., Sun, L. C., Chiu, H. C., \& Wang, J. Y. (2018a). Short- and long-term outcomes of laparoscopic-assisted surgery, mini-laparotomy and conventional laparotomy in patients with Stage I-III colorectal cancer. Journal of Minimal Access Surgery, 14(4), 321-334. http://dx.doi.org/10.4103/ jmas.JMAS_155_17. PMid:29483373.

Chen, L., Gao, H., Liang, J., Qiao, J., Duan, J., Shi, H., Zhen, T., Li, H., Zhang, F., Zhu, Z., \& Han, A. (2018b). miR-203a-3p promotes colorectal cancer proliferation and migration by targeting PDE4D. American Journal of Cancer Research, 8(12), 2387-2401. PMid:30662799.

Chiu, C. C., Lin, W. L., Shi, H. Y., Huang, C. C., Chen, J. J., Su, S. B., Lai, C. C., Chao, C. M., Tsao, C. J., Chen, S. H., \& Wang, J. J. (2019). Comparison of oncologic outcomes in laparoscopic versus open surgery for non-metastatic colorectal cancer: personal experience in a single institution. Journal of Clinical Medicine, 8(6), 875. http:// dx.doi.org/10.3390/jcm8060875. PMid:31248135.

Cui, X., Shen, W., Wang, G., Huang, Z., Wen, D., Yang, Y., Liu, Y., \& Cui, L. (2018). Ring finger protein 152 inhibits colorectal cancer cell growth and is a novel prognostic biomarker. American Journal of Translational Research, 10(11), 3701-3712. PMid:30662620.

Digiacomo, N., Bolzacchini, E., Veronesi, G., Cerutti, R., Sahnane, N., Pinotti, G., Bregni, M., Artale, S., Verusio, C., Crivelli, F., Capella, C., Sessa, F., \& Furlan, D. (2019). Neuroendocrine differentiation, microsatellite instability, and tumor-infiltrating lymphocytes in advanced colorectal cancer with BRAF mutation. Clinical Colorectal Cancer, 18(2), e251-e260. http://dx.doi.org/10.1016/j.clcc.2018.12.003. PMid:30638691.
Fahim, M., Visser, R. A., Dijksman, L. M., Biesma, D. H., Noordzij, P. G., \& Smits, A. B. (2019). Routine postoperative ICU admission after colorectal cancer surgery for the elderly patient reduces postoperative morbidity and mortality. Colorectal Disease, 22(4), 408-415.

Gachpazan, M., Kashani, H., Hassanian, S. M., Khazaei, M., Khorrami, S., Ferns, G. A., \& Avan, A. (2019). Therapeutic potential of targeting transforming growth factor beta in colorectal cancer: rational and progress. Current Pharmaceutical Design, 25(38), 4085-4089. http:// dx.doi.org/10.2174/1381612825666191105114539. PMid:31692434.

Gaspar-Pintiliescu, A., Oancea, A., Cotarlet, M., Vasile, A. M., Bahrim, G. E., Shaposhnikov, S., Craciunescu, O., \& Oprita, E. I. (2020). Angiotensin-converting enzyme inhibition, antioxidant activity and cytotoxicity of bioactive peptides from fermented bovine colostrum. International Journal of Dairy Technology, 73(1), 108-116. http:// dx.doi.org/10.1111/1471-0307.12659.

Hamabe, A., Ogino, T., Tanida, T., Noura, S., Morita, S., \& Dono, K. (2019). Indocyanine green fluorescence-guided laparoscopic surgery, with omental appendices as fluorescent markers for colorectal cancer resection: a pilot study. Surgical Endoscopy, 33(2), 669-678. http:// dx.doi.org/10.1007/s00464-018-6504-6. PMid:30341652.

Igder, S., Mohammadiasl, J., Azadpour, S., Mansouri, E., Ashktorab, H., \& Mokarram, P. (2020). KRAS mutation and abnormal expression of Cripto-1 as two potential candidate biomarkers for detection of colorectal cancer development. Journal of Cellular Biochemistry, 121(4), 2901-2908. PMid:31692030.

Iwamoto, K., Takahashi, H., Fujii, M., Haraguchi, N., Hata, T., Matsuda, C., Yamamoto, H., Mizushima, T., Mori, M., \& Doki, Y. (2019). Correction to: safety of single-site laparoscopic surgery requiring perioperative heparinization in colorectal cancer: propensity scorematched analysis. Annals of Surgical Oncology, 26(Suppl. 3), 892. http://dx.doi.org/10.1245/s10434-019-07839-1. PMid:31531795.

Jouki, M., Rabbani, M., \& Shakouri, M. J. (2020). Effects of pectin and tomato paste as a natural antioxidant on inhibition of lipid oxidation and production of functional chicken breast sausage. Food Science Technology, 40(Suppl. 2), 521-527. http://dx.doi.org/10.1590/fst.26419.

Kim, Y. W., \& Kim, I. Y. (2017). Comparison of the short-term outcomes of laparoscopic and open resections for colorectal cancer in patients with a history of prior median laparotomy. The Indian Journal of Surgery, 79(6), 527-533. http://dx.doi.org/10.1007/s12262-0161520-z. PMid:29217904.

Kojima, Y., Sakamoto, K., \& Okuzawa, A. (2019). Experience of using a spray-type anti-adhesion barrier in laparoscopic surgery for colorectal cancer. Journal of Surgical Case Reports, 2019(3), rjz085. http://dx.doi.org/10.1093/jscr/rjz085. PMid:30949335.

Li, L., Xue, Y., Zhang, H., Liu, Y., Yi, F., \& Dong, Y. (2021). A new polysaccharide isolated from Dendrobium offcinale, stimulates aquaporin-3 expression in human keratinocytes. Food Science Technology, 41(1), 90-95. http://dx.doi.org/10.1590/fst.31119.

Mekic, M. S., Pedisic, I., Sobat, H., Boras, V. V., Kirac, I., Štefančić, L., Šekerija, M., Vrdoljak, B., \& Vrdoljak, D. V. (2018). The role of complete blood count parameters in patients with colorectal cancer. Acta Clinica Croatica, 57(4), 624-629. http://dx.doi.org/10.20471/ acc.2018.57.04.03. PMid:31168198.

Mostafa, H. S., Ali, M. R., \& Mohamed, R. M. (2021). Production of a novel probiotic date juice with anti-proliferative activity against Hep-2 cancer cells. Food Science Technology, 41(Suppl. 1), 105-115. http://dx.doi.org/10.1590/fst.09920.

Pei, J. P., Zhang, C. D., Fan, Y. C., \& Dai, D. Q. (2019). Comparison of different lymph node staging systems in patients with resectable colorectal cancer. Frontiers in Oncology, 8, 671. http://dx.doi. org/10.3389/fonc.2018.00671. PMid:30697530. 
Rafiq, S., Gulzar, N., Huma, N., Hussain, I., \& Murtaza, M. S. (2020). Valuation of anti-proliferative activity of Cheddar cheeses using colon adenocarcinoma (HCT-116) cell line. International Journal of Dairy Technology, 73(1), 255-260. http://dx.doi.org/10.1111/14710307.12665.

Sasso, A., \& Latella, G. (2018). Role of Heme iron in the association between red meat consumption and colorectal Cancer. Nutrition and Cancer, 70(8), 1173-1183. http://dx.doi.org/10.1080/0163558 1.2018.1521441. PMid:30638072.

Tajima, T., Mukai, M., Yokoyama, D., Higami, S., Uda, S., Hasegawa, S., Nomura, E., Sadahiro, S., Yasuda, S., \& Makuuchi, H. (2017). Comparison of hand-assisted laparoscopic surgery (HALS) and conventional laparotomy in patients with colorectal cancer: final results from a single center. Oncology Letters, 13(6), 4953-4958. http://dx.doi.org/10.3892/ol.2017.6035. PMid:28588735.

Wieczorska, K., Stolarek, M., \& Stec, R. (2020). The role of the gut microbiome in colorectal cancer: where are we? Where are we going? Clinical Colorectal Cancer, 19(1), 5-12. PMid:31678050.

Yeh, Y. M., Lee, C. H., Chen, S. H., Lee, C. T., Chen, Y. L., Lin, B. W., Lin, S. C., Chan, R. H., Lee, J. C., Shen, M. R., \& Lin, P. C. (2019).
Comprehensive assessment of HER2 alteration in a colorectal cancer cohort: from next-generation sequencing to clinical significance. Cancer Management and Research, 11, 7867-7875. http://dx.doi. org/10.2147/CMAR.S213247. PMid:31692488.

Zhao, J. K., Chen, N. Z., Zheng, J. B., He, S., \& Sun, X. J. (2014). Laparoscopic versus open surgery for rectal cancer: Results of a systematic review and meta-analysis on clinical efficacy. Molecular and Clinical Oncology, 2(6), 1097-1102. http://dx.doi.org/10.3892/ mco.2014.345. PMid:25279204.

Zhao, X., Liu, J., Liu, S., Yang, F., \& Chen, E. (2019). Construction and validation of an immune-related prognostic model based on TP53 Status in colorectal cancer. Cancers, 11(11), 1722. http://dx.doi. org/10.3390/cancers11111722. PMid:31689990.

Zhou, S., Wang, X., Zhao, C., Pei, W., Zhou, H., Liu, Q., Liang, J., Zhou, Z., \& Wang, X. (2019). Comparison of short-term and survival outcomes for transanal natural orifice specimen extraction with conventional mini-laparotomy after laparoscopic anterior resection for colorectal cancer. Cancer Management and Research, 11, 59395948. http://dx.doi.org/10.2147/CMAR.S209194. PMid:31303795. 